Supporting Information for:

\title{
Alkalinization of Thin Layer Samples with a Selective Proton Sink Membrane Electrode for Detecting Carbonate by Carbonate-Selective Electrodes
}

Sutida Jansod, Majid Ghahraman Afshar, Gastón A. Crespo and Eric Bakker*

Department of Inorganic and Analytical Chemistry, University of Geneva, Quai Ernest-Ansermet 30, CH1211 Geneva, Switzerland

Corresponding Author: eric.bakker@unige.ch 


\section{Reagents and Solutions}

Muti-walled carbon nanotubes (MWCNT), thionyl chloride $\left(\mathrm{SOCl}_{2}\right)$, octadecylamine (ODA), bis(2ethylhexyl) sebacate (DOS), sulfuric acid (97\%), nitric acid (65\%), poly(vinyl-chloride) (PVC, high molecular weight), N,N-dioctyl-3 $\alpha, 12 \alpha$-bis(4-trifluoroacetylbenzoyloxy)-5 $\beta$-cholan-24-amide (carbonate ionophore VII), dioctyl-adipate (DOA), tridodecylmethylammonium chloride (TDMAC), tetrahydrofuran (THF), potassium tetrakis[3,5-bis(trifluoromethyl)phenyl]borate (KTFPB), chromoionophore I, 2nitrophenyloctylether (o-NPOE), tris(hydroxymethyl)aminomethane (Tris), acetic acid, sodium acetate, sodium chloride, sodium hydroxide $(1 \mathrm{M})$ and tetrahydrofuran (THF) were purchased from SigmaAldrich (analytical grade). The synthesis of lipophilic multi-walled carbon nanotubes was performed by following the procedure by Blondeau et al., with some modifications (Xavier Rius-Ruiz, F., BejaranoNosas, D., Blondeau, P., Riu, J., Xavier Rius, F., Anal. Chem. 2011, 83, 5783-5788).

\section{Membrane Electrode Preparation}

Proton Sink membranes: The $\mathrm{pH}$ responsive membrane for consuming hydrogen ions was based on porous polypropylene (PP) membranes (Celgard, $0.237 \mathrm{~cm}^{2}$ surface area, $25 \mu \mathrm{m}$ thickness, and kindly provided by Membrane Wuppertal, Germany) used as a supporting material. The membranes were rinsed with THF for 10 min to remove any contaminants. An excess volume of the cocktail solution $(4 \mu \mathrm{L})$ was deposited on the Celgard membrane when the membrane was completely dry (in a matter of seconds after evaporating THF). The cocktail preparation was explained below for proton sink membrane. The impregnation of the cocktail was found to be instantaneous; to be sure about the impregnation of the Celgard pores, the membrane was let in the Petri Dish for $10 \mathrm{~min}$. The pore filling solution composition is assumed to remain identical to the initial THF-free cocktail. Subsequently, the membrane was conditioned in the $10 \mathrm{mM} \mathrm{HCl}$ solution for $40 \mathrm{~min}$. Finally the membrane was mounted in the Ostec body to use as a proton sink. The inner filling solution was $10 \mathrm{mM} \mathrm{HCl}$. All the solutions were prepared in 10 $\mathrm{mM}$ of $\mathrm{NaCl}$ as background electrolyte. The cocktail of proton sink contained $120 \mathrm{mmol} \mathrm{kg}^{-1}$ of chromoionophore I (mmol per kg of cocktail), $60 \mathrm{mmol} \mathrm{kg}^{-1}$ of KTFPB, $90 \mathrm{mmol} \mathrm{kg}^{-1}$ of ETH 500, 150 $\mathrm{mg}$ of o-NPOE and $1 \mathrm{~mL}$ of THF. The solvent, THF, was only used to dissolve the solid compounds into the plasticizer and was removed by evaporation before casting the membranes.

Probe membranes: A mixture of ionophore, ion exchanger, plasticizer and PVC was used to prepare the cocktail for carbonate and hydrogen ion-selective electrodes. About $8.3 \mathrm{mg}$ carbonate ionophore VII (L'), $0.5 \mathrm{mg}$ TDMAC $\left(\mathrm{R}^{+}\right), 80 \mathrm{mg}$ PVC and $100 \mu \mathrm{L}$ DOA were dissolved in $2 \mathrm{~mL}$ THF solvent for carbonate detection. ${ }^{22}$ The chemical composition for the $\mathrm{pH}$ probe membrane was $15 \mathrm{mmol} \mathrm{kg}^{-1}$ of ionophore I (L) (mmol per kg of coaktail), $5 \mathrm{mmol} \mathrm{kg}{ }^{-1}$ of KTFPB $\left(\mathrm{R}^{-}\right), 135 \mathrm{mg}$ of o-NPOE and $62 \mathrm{mg}$ PVC and $1 \mathrm{~mL}$ THF. $150 \mu \mathrm{L}$ of the carbonate or $\mathrm{pH}$ responsive cocktail $(3 \times 50 \mu \mathrm{L})$ was pipetted and drop cast on glassy carbon electrode that was already covered with the f-MWCNTs (for more details about f-MWCNTs, see reference ${ }^{5}$.

\section{Electrochemical Equipment}

A Metrohm $827 \mathrm{pH}$ meter, a double-junction $\mathrm{Ag} / \mathrm{AgCl} / 3 \mathrm{M} \mathrm{KCl} / 1 \mathrm{M} \mathrm{LiOAc}$ reference electrode, glassy carbon electrode with a diameter of $3.00 \pm 0.05 \mathrm{~mm}$, a platinum-working rod $\left(3.2 \mathrm{~cm}^{2}\right.$ surface area), electrode bodies (Oesch Sensor Technology), a high impedance input 16-channel EMF monitor 
(Lawson), a 765-automatic Dosimat (Metrohm Autolab, Utrecht), and an Autolab PGSTAT101 Metrohm Autolab were used.

Integration of both electrodes in the electrochemical cell

The electrochemical cell consisted of two electrodes (readout and proton sink membrane electrodes) placed exactly in front of each other. ${ }^{7}$ The electrochemical configuration was GClf-MWCNTslreadout membranellsamplellproton sink membranel10mM HCllAgCllAg. The distance between readout electrode (proton or carbonate) and the proton sink was adjusted mechanically. For this purpose, both electrodes were inserted into the electrochemical cell and then a piece of paper $(100 \mu \mathrm{m})$ was tightly placed between them. Afterwards, the paper was removed from the space between the two electrodes and the vessel was filled with the sample solution. Finally, the coulometric protocol was applied to the electrochemical cell.

\section{Electrochemical protocol}

A fully automatized (NOVA software, Autolab) method for consuming protons consists of two steps: i) open circuit potential determination for 5-s at a sampling rate of $10 \mathrm{~Hz}$, (no current flow through the electrochemical cell), ii) cathodic potential pulse at different times (from 100-s to 600-s) at sampling rate of $500 \mathrm{~Hz}$. Simultaneously, a potentiometric determination is accomplished with the proton or carbonate selective sensor. For the Arve river sample no pretreatment was required.

\section{Volumetric Titration Protocol}

The concentration of bicarbonate and carbonate was determined by a reference method to validate the approach. A classical acid-base titration was chosen as a reference method to obtain carbonate and bicarbonate concentration. The bicarbonate concentration was directly determined by adding $0.005 \mathrm{M}$ $\mathrm{HCl}$ as a titrant to the Arve River sample to reach $\mathrm{pH} 4$ (total alkalinity detection). The low carbonate concentration $(\sim \mu \mathrm{M})$ limited the possibility of obtaining carbonate concentration by direct titration. As a result, a defined amount $0.005 \mathrm{M} \mathrm{NaOH}(10 \mathrm{~mL})$ was added to $10 \mathrm{~mL}$ of the Arve river sample. Subsequently, the sample was back titrated with same titrant to obtain carbonate concentration. 

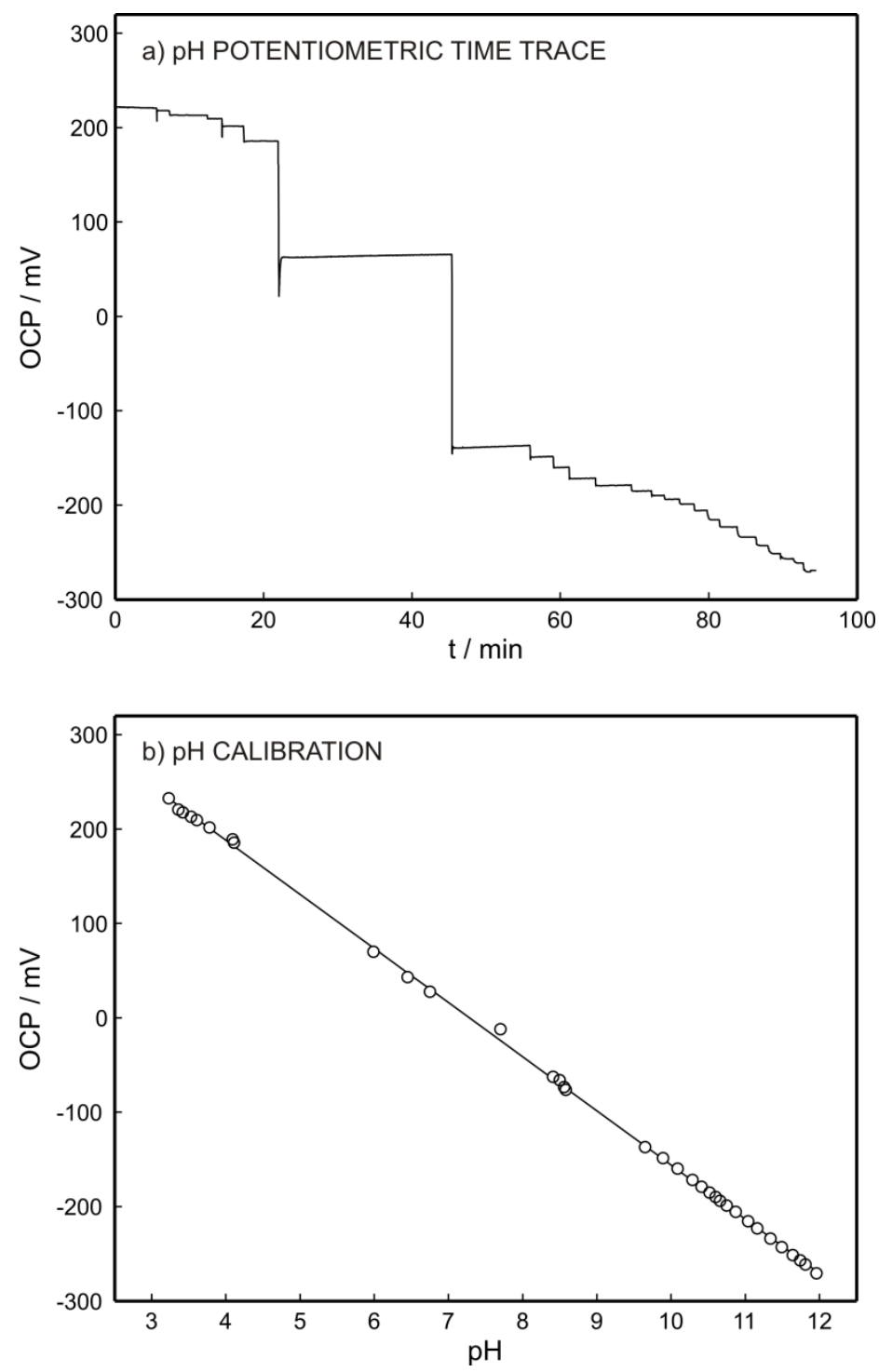

Figure S1. a) Potentiometric time trace of proton-selective membrane obtained in well-buffered solution by using universal buffer $0.01 \mathrm{M}$ within the $\mathrm{pH}$ range of 3 to $12 . \mathrm{b}$ ) $\mathrm{pH}$ calibration curve of the hydrogen ion-selective electrode in the $\mathrm{pH}$ range of 3 to 12. 


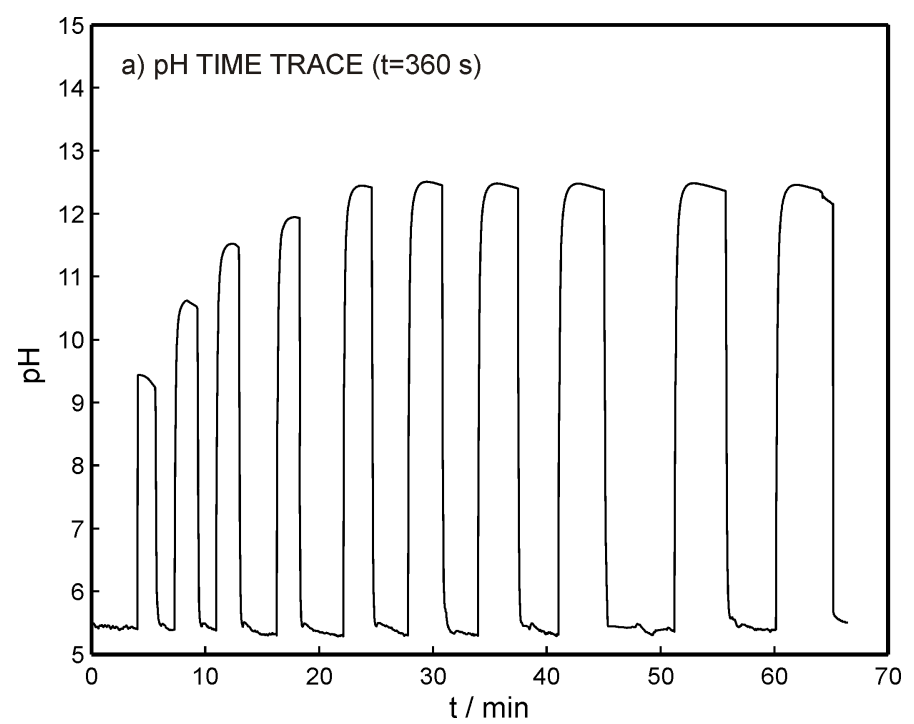

Figure S2. Potentiometric time trace of hydrogen ion-selective membrane as a function of time for applying the potential controlled potential pulse, applied excitation potential within the range of 100 to $1000 \mathrm{mV}$ in steps of $100 \mathrm{mV}$ from left to right at $360 \mathrm{~s}$ at the proton sink membrane. 


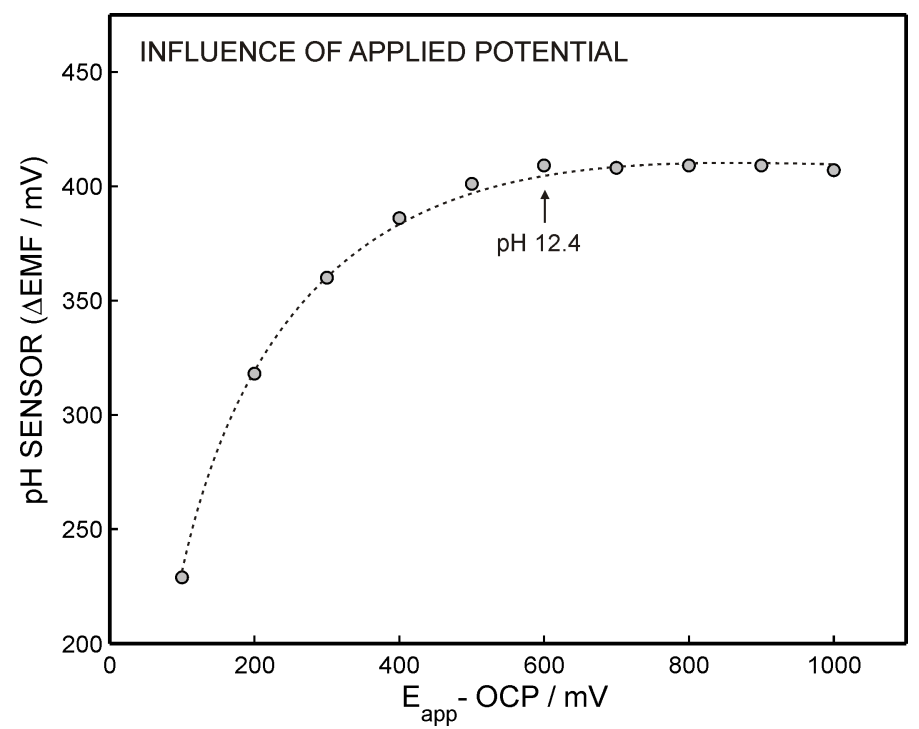

Figure S3. pH response of hydrogen ion-selective membrane as a function of the amplitude of applied potential (from left to right, 100 to 1000 in steps of $100 \mathrm{mV}$ for $360 \mathrm{~s}$ ). 

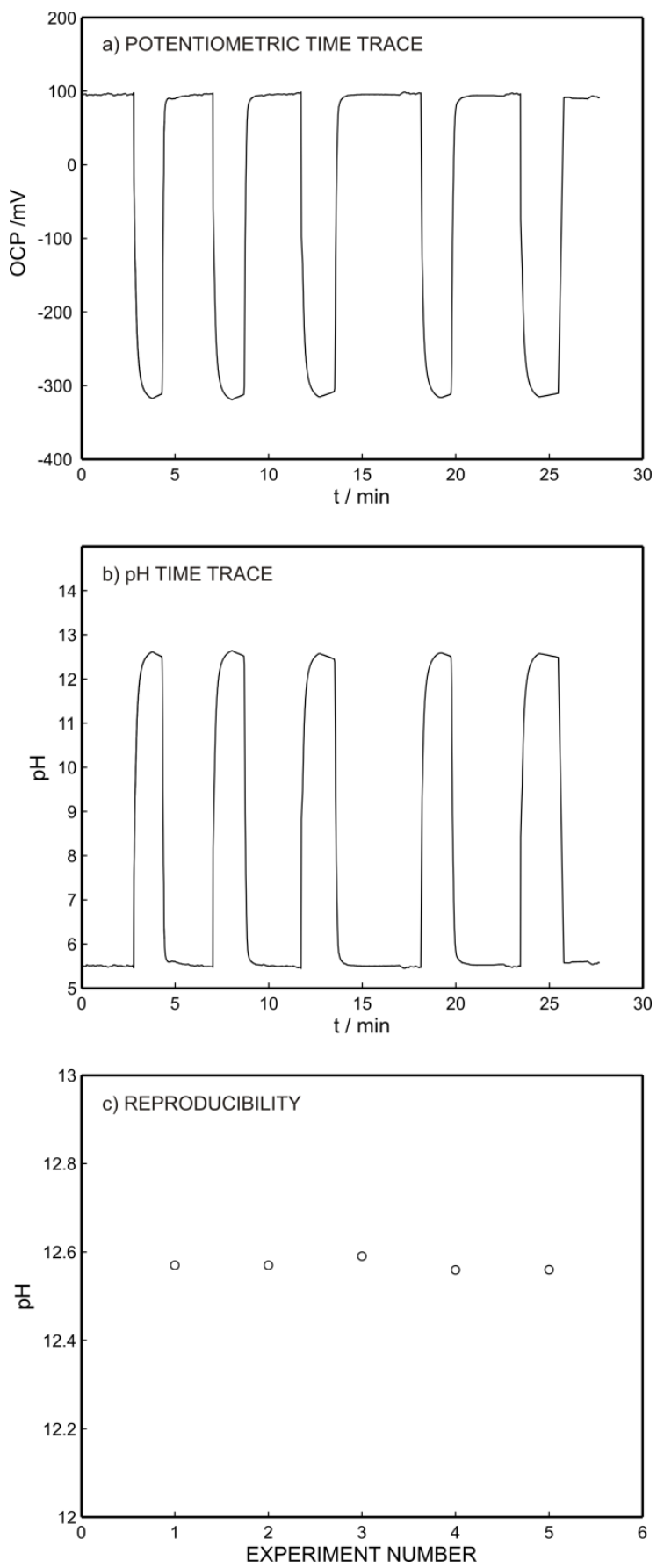

Figure S4. a) Potentiometric time trace of proton-selective electrode by applying five times the potential pulses $(600 \mathrm{mv}$ for $360 \mathrm{~s})$. b) $\mathrm{pH}$ response of proton selective membrane for applying the same potential pulses. c) Reproducibility of $\mathrm{pH}$ readings for repetitive pulses of $2 \% \mathrm{RSD}$ for $360 \mathrm{~s}$ at $600 \mathrm{mV}$. 

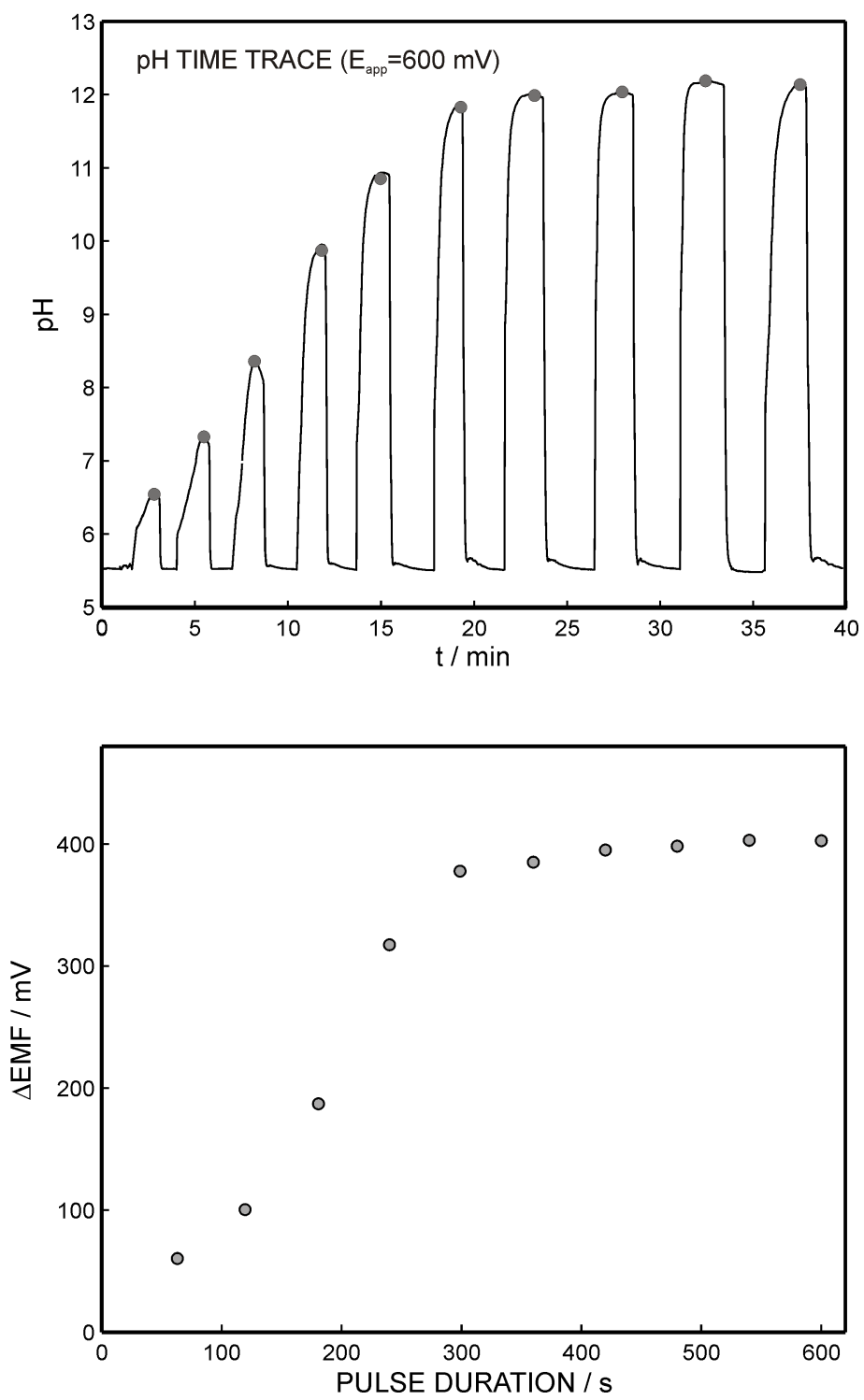

Figure S5 Top: Potentiometric time trace of proton-selective membrane as a function of time for applying the time controlled potential pulse, applied excitation potential within the range of 60 to $600 \mathrm{~s}$ in steps of $60 \mathrm{~s}$ from left to right at $600 \mathrm{mV}$ at the pull proton pump membrane. Bottom: $\mathrm{pH}$ response of protonselective membrane as a function of pulse duration (from left to right, 60, 120, 180, 240, 300, 360, 420, $480,540,600 \mathrm{~s})$ at $600 \mathrm{mV}$ along with the correlation between observed EMF value and pulse duration. 

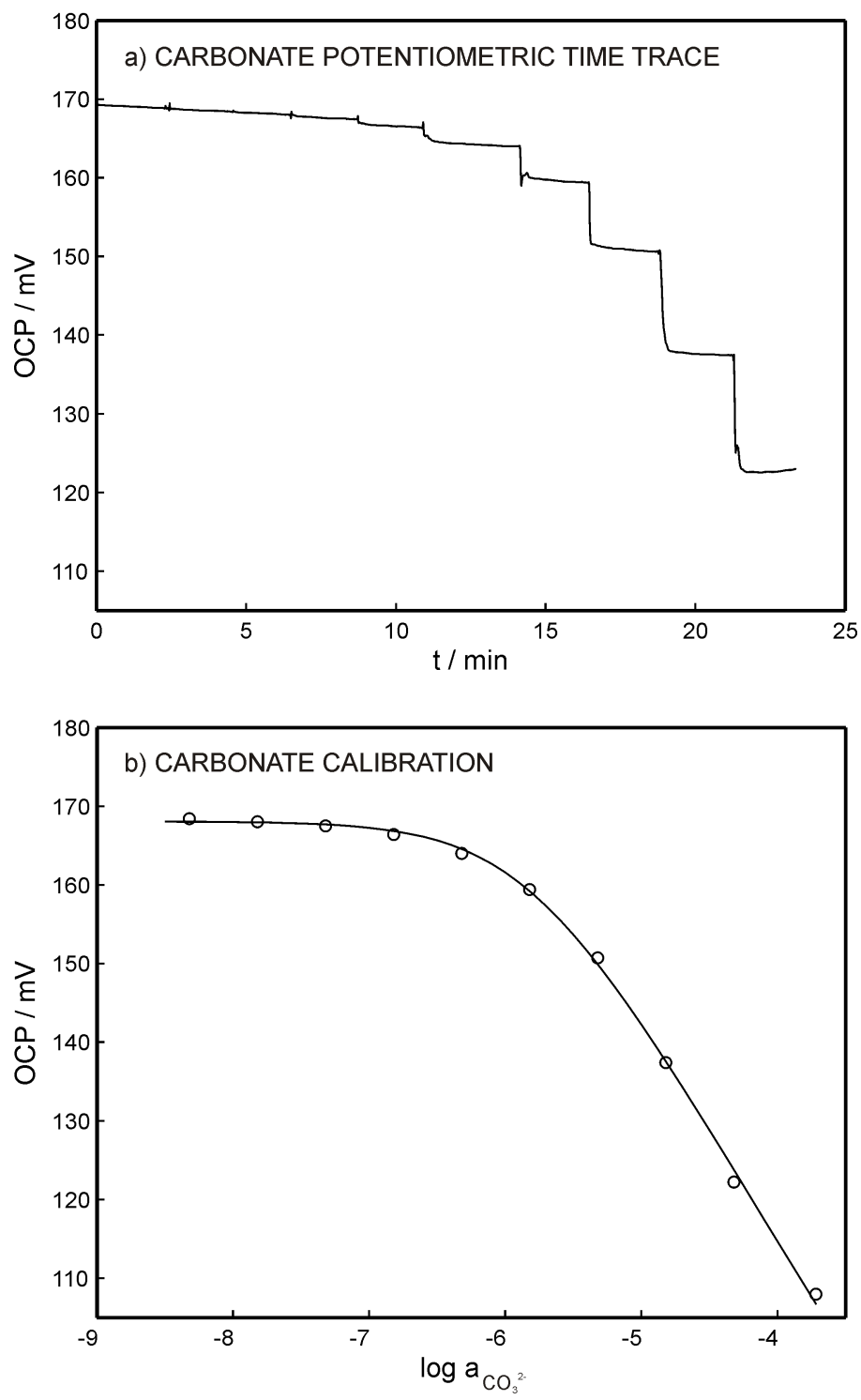

Figure S6. a) Potentiometric time trace of carbonate-selective membrane obtained in well-buffered solution by using $0.1 \mathrm{M}$ Tris buffer at $\mathrm{pH} 9.2$ within the range of $10^{-8}$ to $10^{-3} \mathrm{M}$. b) Potentiometric calibration curve of hydrogen ion-selective electrode in the range of $10^{-8}$ to $10^{-3} \mathrm{M}$ carbonate concentration.] 

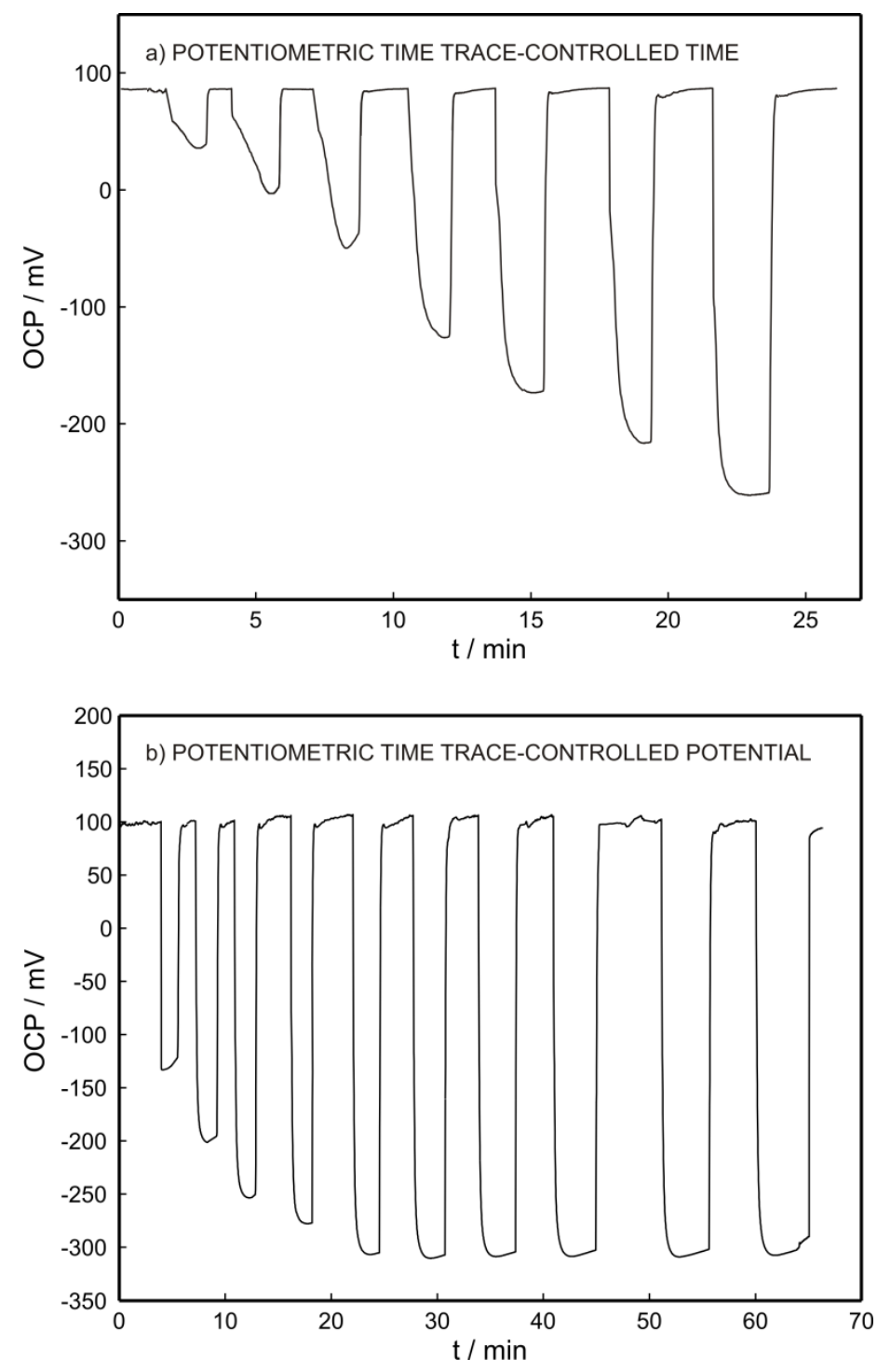

Figure S7. a) Potentiometric time trace of proton-selective membrane as a function of time for applying the time controlled potential pulse, applied excitation potential within the range of 60 to $420 \mathrm{~s}$ in steps of $60 \mathrm{~s}$ from left to right at $600 \mathrm{mV}$ at the pull proton pump membrane. b) Potentiometric time trace of hydrogen ion-selective membrane as a function of time for applying the potential controlled potential pulse, applied excitation potential within the range of 100 to $1000 \mathrm{mV}$ in steps of $100 \mathrm{mV}$ from left to right at $360 \mathrm{~s}$ at the proton sink membrane. 